\title{
Military Health Research in Saudi Arabia: A Call for Action
}

\author{
Weam M. Banjar ${ }^{\text {a }}$ Essam A. Bin Burhan ${ }^{b}$ \\ ${ }^{\mathrm{a} G l o b a l}$ Center for Mass Gathering Center, Ministry of Health, Riyadh, Saudi Arabia; ${ }^{\mathrm{b}}$ Medical Field Military \\ Command, Ministry of National Guard, Riyadh, Saudi Arabia
}

\section{Keywords \\ Military health · Military medicine research program . \\ Combat medic $\cdot$ Military research}

Research sets the foundation to establish evidence that supports informed decision-making process and design data-gathering scheme for planning and quality monitoring purposes. Military medicine is challenging at strategic and operational levels due to complex functional scheme and the need to adapt the requirement-driven military approach. The Gulf War I and II present military medicine with its toughest challenge. Regardless the vast financial support, superior-quality training and cumulative experience, documentation, and research in the field of military medicine is evidently poor. Health care providers at battlefields are very connected to their patients because they serve as an integrated member of a unit [1]. In field operations, health care providers endure the same challenges as their non-medical comrades with added pressure of delivering medical care which leaves health care providers vulnerable to psychological trauma in addition to expected risk of physical trauma [1]. According to an Army Field Manual that addresses health care services in a war zone, the primary objective of a unit-level medical care personnel is to deliver "immediate life-saving measures" [1,2]. In Saudi Arabia, military medicine is receiv-

Karger@karger.com www.karger.com/sjh

Karger"
(C) 2022 The Author(s)

Published by S. Karger AG, Basel

This is an Open Access article licensed under the Creative Common Attribution-NonCommercial-4.0 International License (CC BY-NC) (http://www.karger.com/Services/OpenAccessLicense), applicable to the online version of the article only. Usage and distribution for commercial purposes requires written permission. ing increased attention in order to enhance human capital capacity in term of training and development. Thus, integration of military medical services into the life-cycle of health care system is essential to maintain system sustainability, services quality and allow for experience sharing and services exchange which ultimately will improve the total quality of care and ensures system efficacy, efficiency, quality, and safety. Military health services differ from routine medical services. Military health services focus primarily on delivering life-saving measures to maintain field operations and tactical power. Military training for health care providers at different care levels equip army with quality personnel to support field operation. There are four levels of field-supportive medical services. The first level focusses on life-saving measures at the site of injury with an aim to control bleeding and evacuate. The escalation of service to the second level was taking them to the first-aid station. Next, the care would be escalated to mobile field hospitals. Once stabilization of injury was achieved, the solider will be sent back to the battle field. If the battle field injury was severe, escalation to fourth level becomes necessary. The forth level aim was to evacuate the case to a general hospital $[3,4]$.

Improving military medical/health services required a model of care designed to meet the needs, secure the demands, and ensure future sustainability. Current status assessment serves as a first step to draw an overview and
Correspondence to:

Weam M. Banjar, wbanjarm@moh.gov.sa 
prioritize action items. It allows identifying areas of strengths that should be enforced, defining weaknesses that must be improved, mapping challenges to establish a mitigation plan, and exploring opportunities to design development and improvement schemes. Experience documentation; via archived records review, memoirs assessment, and word-of-the-mouth based on constructive personal interviews; is pivotal to extract the lessons learned. A holistic approach to current status assessment is the cornerstone to establish a comprehensive understanding for priority setting and strategic planning. Two broad categories could identify challenges that military medicine professionals may face: personnel-related and system-related challenges. Personnel-related challenges are often driven by the system-related challenges and include training and development, field reference, and personnel support. System-related challenges are complex due to multi-level and multi-sectorial military structure and include unique nature of medical services, absence of supporting registries or health information system, funding, the need for integration with health care system, and logistics and supply chain management.

Until recently, there had been little consideration of the impact of war on military and civilian health care, particularly trauma care [5]. Review of health research priority agenda for the Ministry of Health in Saudi Arabia indicates the absence of military medicine-related themes [6]. Because it is not feasible to conduct a randomized controlled clinical trials to assess new technologies or practice regimes in the theater of war, well-established registries serve as a data warehouse that could be utilized to conduct retrospective and comparative effectiveness studies to shape and improve military clinical practice and practice guidelines [5]. Registries present the best data source available, due to continuous data feeding and constant data management and quality control, coupled with experience to develop clinical practice guidelines that continue to be refined until high-quality data can be generated to foster a learning health system $[5,7,8]$. National research priority agenda must consider military trauma research and combat causality care research and emphasize on funding and researchers' support. The progress in establishing a military medicine research program should be driven by an overarching goal of minimizing and ultimately eliminating preventable deaths after injury and aiming at improving the total service quality and military personnel well-being. It is important to establish a coherent command system to collect prehospital patient care information. Systematic gathering and examining potentially preventable deaths and prehospital

Military Health Research in Saudi Arabia care data give accurate assessment on the momentum of care compared to other medics [9]. Research and development departments should focus on rearranging existing paradigms for doctrine, human capital, equipment, material, and practice. It is important to balance the research and development investment in the field of military medicine between materialized items and items related to human capital. Data and metrics must be gathered at the point of injury and through the continuum of care to drive the evidence-based decisions [9]. Budget should be carefully allocated to balance between research infrastructure development, conducting research activities, human capital training and development, and leadership.

The war at global and regional levels shed light on the need to establish Military Medicine Research Program (MMRP). MMRP serves an overarching umbrella for research and development departments at different military health authorities and to oversee the process of setting health research priority agenda in collaboration with other health authorities. MMRP focuses on three main domains: infrastructure development, committed to training and development, and opening up to collaborative research activities. The domains are interactive and act as gears that operate the military medicine research movement. Each domain involves multi-sectorial action items. Thus, Research, Development and Innovation Authority in Saudi Arabia may serve as an overarching umbrella that governs the process to develop a conceptual framework that maps the phases to establish MMRP. World War I and II increased US and UK armed forces attention to the increasing demands to improve focus on military health at personnel and care levels. Nevertheless, UK armed forces established military health research programs in collaboration with academic institutes to establish evidence-based military medicine practices. Shortly after Gulf War I and II, US armed forces recognized the need for military health research programs that primarily focused on utilizing available data sources that eventually transformed to building national war injuries registries. Registries set the foundation to prioritize action plan in training, quality of care improvement, and better resource allocation. Military health research had contributed to forecasting and broadcasting to maintain sustainable preparedness and determine evidence-based interventions.

MMRP complements military industry enhancement activities. Military health is unique and research and development departments are essential to oversee research activities and ensure implementation of health research 
priority agenda with respect to related themes. MMRP is the first step to engage professional civilian in military medicine and benefit from health research experience in Saudi Arabia. It is time to initiate the movement toward evidence-based military medicine that meet the local needs and address the demands.

\section{Conflict of Interest Statement}

This to confirm that W.M.B. is an associate editor for the Saudi Journal for Health System Research. However, E.A.B. had no conflict of interest to declare.

\section{Funding Sources}

This to confirm that this editorial had been prepared with no source of funding.

\section{Author Contributions}

W.M.B. developed the conceptual framework, collected evidence, extracted information, critically evaluated literature, analyzed the date, and wrote the initial and final draft. E.A.B. jointly developed the conceptual framework of the commentary with W.M.B., conducted literature search, analyzed the data, and participated in writing the initial and final draft. Both authors have critically reviewed and approved the final version of the manuscript and are responsible for the content. Both authors, also, confirm that they are accountable for all aspects of the editorial.

\section{References}

1 Benshoof C. "Not on my watch: moral trauma and moral injury among combat medics". Thesis, Georgia State University; 2017. Available from: https://scholarworks.gsu.edu/rs theses/52.

2 "Basic Combat Training," GoArmy.com. Available from: http://www.goarmy.com/soldier-life/becoming-asoldier/basic-combattraining.html.

3 Butler FK. Two decades of saving lives on the battlefield: tactical combat casualty care turns 20. Mil Med. 2017;182(3):e1563-8.
4 Maughon JS. An inquiry into the nature of wounds resulting in killed in action in Vietnam. Mil Med. 1970;135:8-13.

5 Rasmussen TE, Kellermann AL. Wartimes lessons shaping a national trauma action plan. N Eng Med J. 2016.

6 Alotaibi A, Saleh WMA, Alshaibani K, Abdulbaqi AH, Alosaimi M. Setting the health research priority agenda for the Ministry of Health $(\mathrm{MoH})$. Kingdome of Saudi Arabia 2020-2025 project. Forthcoming. 2020.
7 National Academies of Sciences, Engineering, and Medicine. A national trauma care system: integrating military and civilian trauma systems to achieve zero preventable deaths after injury. Washington, DC: National Academies Press; 2016.

8 Kotwal RS, Howard JT, Orman JA, Tarpey BW, Bailey JA, Champion HR, et al. The effect of golden hour policy on the morbidity and mortality of combat causalities. JAMA Surg. 2016;151:15-24.

9 Butler FK. Two decades of saving lives on the battlefield: tactical combat casualty care turns 20. Mil Med. 2017;182(3):e1563-8. 